\title{
Патриотический дискурс в молодежной среде: поиски оптимальной модели коммуникации
}

\author{
Юрий Ершов \\ Кирилл Маркелов \\ Татьяна Черепанова
}

\begin{abstract}
В статье предлагается осмысление концептов патриотизма и воинской героики в медиадискурсе и их роли в воспитательной работе с молодежью. Авторы, в частности, выявляют и анализируют проблемы, связанные с недостатком образованности и гражданственной зрелости студентов. На основе данных социологического исследования выносится на обсуждение модель молодежной патриотической коммуникации, которая может быть реализована с учетом возрастной специфики аудитории на двух важнейших площадках - медийной и образовательной. Ключевые слова: медиадискурс, патриотизм, молодежь, образование, воспитание.
\end{abstract}

DOI: 10.30547/mediaalmanah.5.2020.7482

\section{Введение}

Изучение интернет-коммуникаций как фактора общественно-политических процессов стало одним из ведущих направлений медиаисследований (Owen, 2017; Gottfried, Shearer, 2016; Вырковский, Колесниченко, 2020) . Внутри этой сферы научных исследований выделяется изучение молодежного медиапотребления, поскольку именно молодые люди быстрее других аудиторных групп осваивают форматы и язык новых медиа и, можно сказать, начинают жить в социальных сетях. Молодежный вопрос изучают социологические службы и университетские коллективы, среди которых видное место занимает Центр молодежных исследований Санкт-Петербургской школы социальных и гуманитарных наук НИУ ВШЭ. На счету Центра более 80 исследований, проведенных под руководством Елены Омельченко (Omelchenko, Poliakov, 2017). Институт социологии Федерального научно-исследовательского социологического центра Российской академии наук провел исследование «Молодежь новой России: образ жизни и ценностные приоритеты» (2007). Ученые факультета журналистики МГУ имени М.В. Ломоносова выполнили большое исследование по медиапотреблению молодежи (Дунас, Вартанов, Кульчицкая, Салихова и др., 2020). Несмотря на то что публикаций, исследовательских отчетов 
и научных сборников достаточно много и количество их растет, нельзя определить лидера мнений в изучении медиапрактик.

Поскольку новых концепций и теоретически значимых результатов исследований медиапрактик пока нет, в государственной молодежной политике не используются научные данные, которые помогли бы управленцам выстроить коммуникации с этими возрастными группами. В мае 2019 г. одним из шести ключевых показателей эффективности для управлений внутриполитического блока администрации Президента России Владимира Путина было определено повышение доли активной, патриотически настроенной молодежи. Чтобы повысить уровень «информированности органов государственной власти о влиянии информационной среды на формирование взглядов подрастающего поколения»1, президент поручил правительству регулярно проводить в Интернете исследования потребительских предпочтений и особенностей поведения молодежной аудитории. Безусловно, академическому сообществу и университетской науке важно понять, как строить коммуникацию с молодежью и могут ли в этом общении использоваться концепты патриотизма и героики. В связи с этим встает вопрос: насколько патриотический дискурс может быть реализован в данной коммуникации? И почему необходимо разработать коммуникативную модель?

Коммуникативная модель - это некая упрощенная (схематизированная) форма коммуникации. С помощью этой модели (ее настройки) можно будет перезагрузить государственную молодежную информационную политику в сфере патриотического воспитания и образования, придав ей важный социализирующий импульс развития, без которого встраивание молодого человека в систему общественных и профессиональных отношений затруднено. Героические символы военного времени всегда имели большое воспитательное значение и способствовали адаптации молодежи к существующему социальному порядку.

Вначале определимся с терминами. Под патриотической коммуникацией мы понимаем систему взаимоотношений в обществе, идейным стержнем которой является патриотизм как некий эталон гражданского поведения. Причем патриотическая коммуникация, на наш взгляд, в идеале должна являть собой синтез двух начал - чувственного и интеллектуального, которые усиливают и дополняют друг друга в процессе получения и обмена информацией патриотического характера. В практическом ключе это выражается в следующем: патриотическая коммуникация призвана усиливать чувство патриотизма у молодежи и способствовать увеличению уровня осведомленности студентов и школьниковстаршеклассников о героях и героических событиях советской и российской истории.

Патриотическую коммуникацию с участием молодежи можно рассматривать с различных точек зрения. Например, ее можно проанализировать как некий самостоятельный социальный феномен, рассмотреть в качестве инструмента государственной пропаганды или, более локально, в качестве инструмента государственной информационной политики. А в перспективе - разработать научно обоснованную теорию молодежной патриотической коммуникации с целью ее более детального изучения для системного применения на практике. Мы же в данной статье ограничимся представлением основных видов и направлений дискурса в рамках патриотической коммуникации и вынесем на обсуждение наиболее важные моменты проекта модели патриотической коммуникации для молодежи.

\section{Методология исследования}

Перед исследователями ставилась цель выявить и проанализировать образы героев и особо значимые в судьбе городагероя Севастополя трагические военные 
события, закрепленные в сознании его молодых жителей. При этом особая роль в исследовании отводилась роли средств массовой информации и коммуникации, в частности документального и художественного кинематографа, интернет-ресурсам. Выборка формировалась исходя из общей совокупности молодежи Севастополя, обучающейся в высших, средних специальных учебных заведениях, а также в старших классах общеобразовательных школ. В исследовании приняли участие 444 респондента: 35,6\% - в возрасте от 16 до 18 лет, 53,7\% - от 19 до 24, 10,7\% - старше 25 лет.

В Севастополе несколько высших учебных заведений, самый крупный - Севастопольский государственный университет (число опрошенных студентов разных курсов 67\%). Второй по численности вуз - филиал МГУ имени М.В. Ломоносова в г. Севастополе (число опрошенных студентов - 4,2\%). Представлены в выборке студенты и других филиалов российских вузов (1\%), а также учащиеся колледжей (18\%) и школьники (1,6\%). Студенты вузов и учащиеся колледжей, проживающие в городе постоянно, но обучающиеся не в Севастополе, составили 2,5 и 0,6\% соответственно. Также в выборке представлены нигде не обучающиеся в настоящий момент молодые люди - 5,1\% от общего количества опрошенных. Генеральная совокупность молодежи в возрасте от 15 до 25 лет - 42 500. Репрезентативная выборка по месту обучения и возрасту составила 444 респондента. Отбор квотный, случайный, погрешность - 4,54.

Для реализации исследовательских целей выборка была условно разделена на две группы. Первая группа объединила респондентов, которые на вопрос «Где прошло ваше детство и юность» ответили «В Севастополе», что указывает на то, что молодые люди включены в исторический контекст Севастополя, социализированы в его культуру и систему ценностей. Во вторую группу вошли респонденты, которые выбрали вариант ответа «В Крыму» и «За пределами Крыма», в Севастополе они проживают недавно, не заканчивали общеобразовательную школу и не являлись членами местных патриотических и других общественных организаций. Выделение данных групп в исследовании позволит выявить отличия в картине исторических представлений и знаний молодежи Севастополя и определить роль средового фактора в их формировании.

Девять вопросов, предложенных респондентам, были систематизированы по трем модулям. Первый модуль определил общие знания о событиях в Севастополе. Второй - показал знания респондентами наиболее известных героев военных событий, а также их заслуг и подвигов. Третий позволил выявить источник знаний. Также был задан открытый инвариантный вопрос, целью которого было выявить понимание молодежью концепта патриотизма.

\section{Основные результаты опроса}

«Какие события происходили в Крыму и Севастополе в 1853-1856 гг.?» На этот вопрос большинство молодых людей ответило правильно, назвав Восточную (Крымскую) войну (84\%). Доля респондентов, не знающих, о каких событиях идет речь, составила 9,3\%, остальные отметили другие события, имевшие место в России, но в другой исторический период. Это указывает на то, что в целом молодежь знает основные вехи истории Севастополя. Тем не менее некоторая доля молодых людей не имеет базовых знаний истории не только Севастополя, но и России.

Второй вопрос модуля «Вторая оборона Севастополя во время Великой Отечественной войны вошла в историю как проявление..." позволил выявить знания не столько о событии, сколько о его оценках, принятых в обществе, и фактах Второй обороны Севастополя в 1941-1942 гг. Здесь ответы были также достаточно однородны и выявили высокий уровень понимания сути 
события. Более 81\% молодежи разделяют основную идею о том, что Вторая оборона Севастополя вошла в историю благодаря массовому героизму его защитников, не только солдат и моряков, но и мирных жителей города (к сожалению, около 10\% молодых людей затруднились с ответом). $16,7 \%$ молодых людей оценили заслуги высшего военно-морского командования, и это нельзя назвать в корне неверным: на слуху имена выдающихся адмиралов и генералов, чьими именами названы улицы и площади Севастополя. Однако более 9\% молодых людей считают, что именно ошибки командования привели к сдаче города, а $4 \%$ респондентов полагают, что провал обороны можно объяснить предательством (при этом не уточнялось, кто именно и кого предавал).

Второй модуль направлен на выявление в памяти молодых севастопольцев не только имен героев, но и их должностей, званий и специализации. В первом вопросе было предложено выбрать из списка известных в разное время севастопольских героев тех, которые имеют отношение к указанному периоду (1853-1856 гг.). Количество ответов не ограничивалось. Больше всего, а именно 67 и 58\% респондентов, выбрали, соответственно, имена адмиралов П.С. Нахимова и В.А. Корнилова. Можно увидеть, что значительная часть молодых людей не имеют представления об адмиралах, погибших при обороне бастионов Севастополя. Еще у меньшего числа молодых людей (по 46,3\%) Первая оборона ассоциируется с именами Даши Севастопольской и Петра Кошки. Большинство респондентов не знали, кто все эти люди, к какому периоду истории Севастополя они имеют отношение. И только четверть опрошенных определила Колю Пищенко как героя этого времени. Соответственно, для 75\% принимавших участие в опросе имя этого молодого защитника города неизвестно. Этот факт, безусловно, не может не огорчать, поскольку именем Коли Пищенко названа одна из улиц центральной части Нахимовского района Севастополя.

Во втором вопросе модуля нужно было соотнести имена героев Первой обороны с их должностями, званиями и специализацией. Ответы респондентов продемонстрировали довольно низкий уровень знаний о роде деятельности героев, особенно учитывая, что память о них увековечена в памятниках, названиях площадей, проспектов, больниц и библиотек. Таким образом, мы пришли к выводу, что у современной севастопольской молодежи недостаточно сформированы знания о героях Первой обороны и их заслугах, благодаря которым они увековечили свои имена в пантеоне героев Крымской войны. Особенно это касается рядовых участников обороны, не имевших званий и высоких чинов, таких как матрос Петр Кошка и юный артиллерист Коля Пищенко, принявший на себя командование батареей после гибели своего отца.

Третий вопрос модуля был направлен на выявление знаний о событиях и героях Великой Отечественной войны, а именно о Второй обороне Севастополя в период с ноября 1941 г. до июля 1942 г., когда высшее военное командование приняло решение о снятии обороны города и эвакуации бойцов и командиров. В результате можно увидеть, что менее половины опрошенных правильно выбрали имена людей, чья жизнь связана с Великой Отечественной войной. В.Д. Ревякина, руководителя севастопольского подполья периода оккупации Крыма, правильно указали 53\% молодых людей. у $42 \%$ и $39 \%$ респондентов Вторая оборона ассоциируется, соответственно, с Л.М. Павличенко и Ниной Ониловой. 41\% указали, что генерал-майор П.Г. Новиков имеет отношение к этому периоду. Таким образом, более половины молодых севастопольцев не только не знают истории своего города, но и имеют достаточно слабые представления о героях ближайшей истории. Отметим, что даже имя В.А. Корнилова, который 
в предыдущих вопросах представлен как участник Первой обороны, почти $25 \%$ респондентов связывают с событиями XX в., так же как и имя адмирала М.П. Лазарева.

Кем была Нина Онилова, знает половина опрошенных молодых людей. Больше всего правильных ответов получено о генерал-майоре П.Г. Новикове и снайпере Людмиле Павличенко, 56\% и 58\% соответственно. Знания о том, чем прославилась Людмила Павличенко, обусловлены, на наш взгляд, успешным прокатом художественного фильма «Оборона Севастополя». Молодежь в основном хорошо приняла блокбастер о Великой Отечественной войне, фильм запомнился. На волне популярности военной тематики в кинематографе, в сочетании с востребованностью у молодежной аудитории жанра боевика, героическая судьба Людмилы Павличенко стала широко известна. Однако даже этот факт не означает, что образ героя закрепился в сознании молодежи достаточно прочно, т.к. зачастую герой блокбастера не ассоциируется с реальным героем.

Третий модуль посвящен выявлению источников информации о героях Первой и Второй обороны и в целом знаний о событиях Великой Отечественной войны, указанных самими респондентами. В ряде случаев при подобной формулировке вопроса респонденту трудно объективировать источник знаний, поэтому было предложено восемь вариантов ответов, из которых выбрать можно было три.

Формирование знаний об историческом прошлом своей страны, ее трагических и победоносных страницах происходит как спонтанно, так и в организованной форме. На всех этапах социализации ребенок интегрирован в духовно-ценностную систему своей культуры. Институты социализации, такие как семья, СМИ, школа, система внешкольного образования и др., включены в единую общероссийскую систему смысловых и идеологических координат, по-своему и на своем уровне транслируя ее подрастающим поколениям. Попытка выявить источник знаний об исторических событиях, сражениях и героях позволит объективировать роль того или иного социального института в воспитании патриотической молодежи. Однако надо помнить, что ответы на подобные вопросы не являются фактологическими, а относятся скорее к субъективным переживаниям и оценкам респондентов.

Полученные данные позволяют определить, какие источники знаний о героях Севастополя молодые люди считают наиболее значимыми в формировании их знаний. Почти 59\% респондентов отдали приоритет школе, указав, что преимущественно в этом образовательном учреждении они узнали о героях обороны Севастополя. Однако в школьной программе по общей истории для старших классов информации о конкретных сражениях на территории Севастополя мало. Остается предполагать, что севастопольские школьники знакомились с историей своего города и его защитников на специальном курсе «Севастополеведение», предусмотренном в начальной школе.

Как показал опрос, студенты, которые не обучались в севастопольских школах, имеют в целом более слабое представление о героях Первой и Второй обороны. На вопрос об источнике знаний эта группа указала в качестве основного источника музеи и архивы, а также Интернет, который уступил школе лишь 3\%. В отличие от ребят, выросших не в Севастополе, местная молодежь (78\%) указала школу как основное место формирования знаний (этот показатель в 1,5 раза превысил значения по музеям и архивам). Местные и неместные ребята по-разному оценили семью, и это не случайно. Для севастопольцев с детства является привычным посещение торжественных мероприятий, исторических праздников и реконструкций как значимого семейного события. Вызвало некоторое удивление то, что ребята в качестве источника информации указали музеи и архивы. 
Вероятно, посещение музеев в юном возрасте становится волнующим событием, врезаясь в память на долгие годы.

Последним вопросом модуля «Из каких источников вы преимущественно получаете знания о военном прошлом Севастополя?» мы пытались подтвердить валидность предыдущего и конкретизировать источник знаний о героях севастопольских сражений. Результаты также распределили по двум группам. Архивы и музеи заняли первую позицию как источник исторической информации в обеих группах. Далее разместились документальное кино у первой группы и художественное кино у второй. Доля художественной и учебной литературы также преобладает у первой группы, тогда как Интернет в качестве источника выбран респондентами из второй группы. Вариант ответа «Ничего из названного» выбран почти четвертой частью респондентов из второй группы, тогда как ребята, выросшие в Севастополе, сумели конкретизировать источник знаний о героическом прошлом и героях города.

\section{Обсуждение форматов и описание коммуникационной модели}

В дискуссионном порядке предлагаем функциональное деление патриотической коммуникации с участием молодежи на следующие форматы:

а) образовательный форум (реализация образовательных программ для молодежи, связанных с героикой прошлого и настоящего, отечественной историей, военными и трудовыми подвигами наших соотечественников);

б) медиафорум (публикации в СМИ и электронных медиа, провоцирующие молодежь на социальную дискуссию по основным вопросам отечественной истории, ключевым моментам героического прошлого и настоящего нашей страны);

в) промокоммуникация (привлечение молодежи в качестве аттрактирующего начала продвижения патриотических идей и концептов, а также организатора патриотической коммуникации в обществе);

г) экшн-коммуникация (привлечение молодежи к участию в социально значимых действиях, связанных с темой героики и патриотизма: историческими реконструкциями, парадами, почетными караулами, конкурсами, праздниками, специальными образовательными программами и прочими социальными актами).

Основные направления молодежного патриотического дискурса следует вырабатывать с учетом интересов и мнений молодежи, а также тех ключевых и болевых точек отечественной истории, которые являются информационными поводами и служат объектом внимания и предметом обсуждения в современном российском обществе. Считаем, что для более детального выявления реперных тем патриотической коммуникации необходимо провести дополнительное исследование. Тем не менее уже сейчас, обладая базовой социологической информацией, можно выделить некоторые из важнейших тем российского прошлого и настоящего, которые носят дискуссионный и в то же время дискурсивный характер, заслуживая целенаправленного погружения в информационное поле патриотической коммуникации в молодежной среде.

Перечислим некоторые из тем, имеющих отношение к проблеме нашего исследования (героика Крымской войны 1853-1855 гг., в частности Первой обороны Севастополя, и Великой Отечественной войны 1941-1945 гг., в частности периода обороны, оккупации и освобождения Севастополя в 1941-1944 гг.).

1) Памятник затопленным кораблям: был ли у адмирала П.С. Нахимова другой выход?

2) Почему стали известными Даша Севастопольская и матрос Петр Кошка? Интересные факты из биографии героев, требующие обсуждения.

3) Новаторские идеи хирурга Н.И. Пирогова в Крымской войне 1853-1855 гг. Роль 
его идей в развитии отечественной и мировой военной стратегической мысли.

4) Что было необычного в «Севастопольских рассказах» Л.Н. Толстого? Почему они стали популярными в свое время?

5) Адмирал В.А. Корнилов: причины популярности у матросов (Первая оборона Севастополя).

6) Управленческий подвиг адмирала Ф.С. Октябрьского, совершенный 22 июня 1941 г., и его стратегическое значение для обороны Севастополя.

7) Подвиг и трагедия 35-й Береговой батареи при обороне Севастополя в 19411942 гг.

8) Подвиг и трагедия севастопольского подполья и крымских партизан периода Великой Отечественной войны.

9) Женщины-герои в обороне и освобождении Севастополя 1941-1944 гг.

10) Сапун Гора: штурм в условиях тотальной обороны немцев. Малоизвестные факты.

Чтобы молодежные исторические форумы не походили на традиционные, зачастую заштампованные и поэтому вызывающие отторжение школьные «уроки мужества», было бы разумно максимально расширить героическую тематику, выйдя за рамки двух указанных войн, и дополнить ее историософической проблематикой, заставляющей думать и делать аргументированный выбор в пользу той или иной исторической концепции. Иначе говоря, в модель патриотической коммуникации целесообразно ввести элемент диалектического взгляда на события и предоставить молодежи свободу исторического конструирования действительности. С этой целью можно устраивать специальные творческие конкурсы, диспуты, квесты на самые важные исторические темы.

Наше практическое предложение состоит в том, что основу модели молодежной патриотической коммуникации следует формировать через методологический синтез двух коммуникативных площадок - образовательной и медийной. Образовательную платформу мы предлагаем формировать по двум основным направлениям - старшие классы средней школы (с возможным последующим присоединением колледжей) и высшие учебные заведения. Деление на довузовское и вузовское патриотическое образование представляется обоснованным в силу интеллектуальных и психологических отличий школьников и студентов. Поэтому модель молодежной патриотической коммуникации предполагает создание и апробацию с последующей корректировкой двух методически последовательных и контентно взаимодополняющих факультативных учебных курсов общим объемом 24 академических часа каждый.

Учебные курсы будут составлены в рамках регионального гранта РФФИ и в случае утверждения в Департаменте образования и науки Севастополя получат шанс пройти апробацию в школах и вузах города уже в следующем учебном году. В этой связи мы предлагаем следующие условные названия учебных курсов: для школ - «Герои и подвиги в отечественной истории», для вузов - «Спорные вопросы отечественной истории». Они должны быть составлены таким образом, чтобы одному и тому же молодому человеку было интересно прослушать один учебный курс в школе, а другой - в вузе, что позволит органично дополнить ранее полученные в школе знания патриотического характера.

Вторая важная площадка молодежной патриотической коммуникации - медийная. Для ее формирования, на наш взгляд, необходимо:

1) Наличие стержневого СМИ, в идеале медиахолдинга, созданного специально для целей патриотического воспитания и образования молодежи. Холдинг должен быть неформальным, тематически ориентированным на молодежь и максимально погруженным в ее реальную (а не выдуманную) проблематику, в другом случае 
он будет малоинтересен, и его пропагандистская функция будет сведена к нулю.

2) Роторный принцип формирования ключевых дискуссионных тем, предполагающий постоянный поиск, генерирование и обновление острых актуальных исторических и историософских сюжетов для общественной дискуссии в массмедиа. Дискуссионные темы подбираются на основе результатов социологических исследований с учетом популярности в современном российском обществе.

3) Интерактивность. Данный принцип призван вовлечь в патриотическую коммуникацию наиболее популярные в молодежной среде социальные сети, в первую очередь "ВКонтакте» и Instagram, с целью привлечения молодых людей для участия в различных конкурсах, квестах, проектах патриотического характера. Предполагается создание специальных групп, страниц, аккаунтов, вызывающих интерес у молодежи своей проблематикой и побуждающих поучаствовать в обсуждении важных исторических тем.

4) Креативность. Принцип креативности предполагает наличие драматургии в медийныхтекстах - захватывающего сюжета, интриги, кульминации, развязки. Кроме того, необходимо использовать специфические выразительные средства: образность, символичность, метафоричность, парадоксальность, специфический сленг и другие элементы привлечения и удержания внимания молодежной аудитории.

Предлагаемая модель носит дискуссионный характер и может уточняться по мере реализации ее на практике.

\section{Заключение}

Патриотическая коммуникация сегодня воспринимается многими молодыми людьми как навязанная, несовременная. Проведенное нами социологическое исследование показывает, что молодежь очень неоднородна по своим историческим знаниям. Многие осведомлены о героических адмиралах и генералах, именами которых названы улицы, но не знают имен героев, добровольцев и рядовых, совершивших подвиги во время Первой и Второй обороны Севастополя.

Семья и школа по-прежнему играют главную роль в усвоении традиций почитания героики прошлого. Однако для глобализованного мира, в котором люди становятся более мобильными и менее укорененными, важным полем формирования патриотизма становится музейно-архивная среда и медиапространство, включая художественное и документальное кино, телепрограммы, интернет-ресурсы. Имена героев запечатлелись в памяти именно благодаря тому, что их образы персонализированы, подвиги визуализированы и эмоционально окрашены. Мы предлагаем учитывать особенности молодежных медиапрактик, связанных с ролью экранных искусств, предпочтением неформальных способов коммуникации, интерактивным общением в социальных сетях и когнитивными механизмами меметики. Студенческие СМИ, работая сразу на двух площадках - медийной и образовательной, могут реализовать ту модель молодежной патриотической коммуникации, которая описана в данной статье как оптимальная.

Исследование выполнено за счет средств гранта РФФИ (проект № 20-412-920001).

\section{Примечания}

1 Сайт Президента России. Перечень поручений по итогам заседания Совета по реализации государственной политики в сфере защиты семьи и детей. Дата пуб- 
ликации: 14 октября 2019 г. Режим доступа: http://kremlin.ru/acts/assignments/ orders/61841

\section{Библиография}

Вырковский А.В., Колесниченко А.В. Новые медиа как площадки для политического дискурса в странах постсоветского пространства // МедиаАльманах. 2020. № 1. С. 48-59. DOI: 10.30547/mediaalmanah.1.2020.4859

Дунас Д.В., Вартанов С.А., Кульчицкая Д.Ю., Салихова Е.А. и др. Мотивационные факторы медиапотребления российской цифровой молодежи: результаты пилотного исследования // Вестн. Моск. ун-та. Сер.10: Журналистика. 2020. № 2. С. 3-27. DOI: 10.30547/ vestnik.journ.2.2020.327.

Молодежь новой России: образ жизни и ценностные приоритеты: аналит. доклад. М.: Ин-т социологии, 2007. Режим доступа: https://www.isras.ru/analytical_report_Youth.html

Gottfried J., Shearer E. (2016) News Use Across Social Media Platforms 2016. Research Report. Washington, D.C.: Pew Research Center. Режим доступа: https://assets.pewresearch.org/ wp-content/uploads/sites/13/2016/05/PJ_2016.05.26_social-media-and-news_FINAL-1.pdf

Omelchenko E., Poliakov S. (2017) Everyday Consumption of Russian Youth in Small Towns and Villages. Sociologia Ruralis 58 (3): 644-664. DOI: 10.1111/soru.12197

Owen D. (2017) The Age of Perplexity: Rethinking the World we Knew. Radically Reassessing "The Economic». Madrid, BBVA, OpenMind, Penguin Random House Grupo Editorial. 